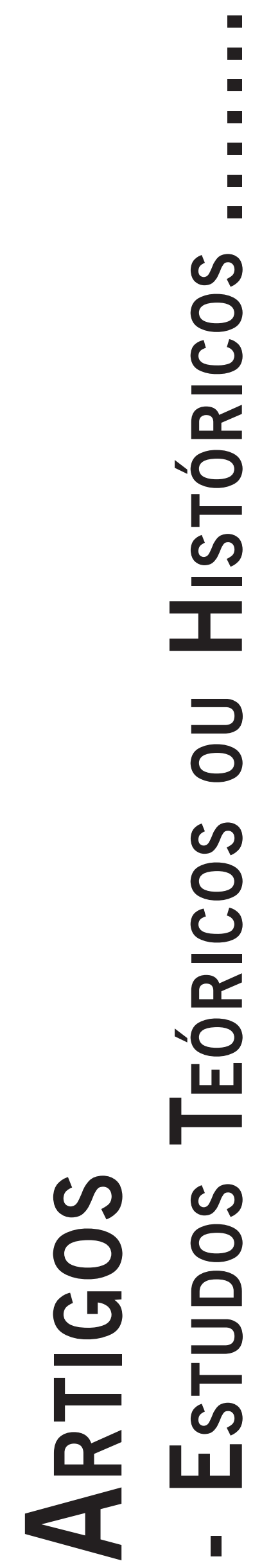




\title{
FUNCIONALISMO E PRAGMATISMO NA TEORIA DE CARL ROGERS: APONTAMENTOS HISTÓRICOS
}

\author{
Functionalism and pragmatism in Carl Rogers' theory: historical appointments
}

Funcionalismo y pragmatismo en la teoría de Carl Rogers: notas históricas

Paulo Collho Castelo Branco

SÉRGIO DIAS CIRINO

\begin{abstract}
Resumo: É possível identificar, na teoria de Carl Rogers, diversas influências que merecem ser revisitadas. É sabido que ele foi um pensador atento ao contexto de ideias que afetaram a cultura acadêmica estadunidense. Tal atenção dialoga com a complexidade de diversas influências sobre sua obra. Este artigo objetiva analisar algumas ideias psicológicas e filosóficas que influenciaram Rogers. Entende-se que exerceram influências diretas no pensamento rogeriano: o Funcionalismo de John Dewey, Leta Hollingworth e Kurt Goldstein; e o Pragmatismo de John Dewey e William Kilpatrick. Segundo uma perspectiva metodológica histórica-crítica, elucida-se como cada perspectiva de influência se desenvolveu nos EUA, nas universidades de Chicago e de Columbia. Em seguida, identificam-se os aportes contatados e elaborados por Rogers de cada expoente mencionado. Constata-se que essas apropriações, embora pontuais, foram importantes para a circulação de Rogers no contexto acadêmico estadunidense. Contudo, incorre equívoco afigurar Rogers, exclusivamente, como um psicólogo funcionalista ou pragmatista, dado que ele não deu continuidade a essas perspectivas. O estudo, finalmente, destaca a necessidade de aprofundar investigações sobre outras bases históricas de influência na teoria rogeriana.
\end{abstract}

Palavras-chave: Carl Rogers; Funcionalismo; História da Psicologia; Pragmatismo; Terapia Centrada no Cliente.

\begin{abstract}
It is possibly to identify in the theory of Carl Rogers many influences that deserve to be revisited. It is known that he was a careful thinker of the context about some ideas that affected the American academic culture. Such attention dialogs with the complexity of many influences on his work. This article aims to analyze some psychological and philosophical ideas that influenced Rogers. It is understood that the followings theories influenced directly Rogers' thought: the Functionalism of John Dewey, Leta Hollingworth and Kurt Goldstein, and the Pragmatism of John Dewey and William Kilpatrick. Through a critical-historical methodological perspective, it is elucidated how each perspective of influence was developed in the USA, in the universities of Chicago and Columbia. After that, we identified the theories contacted and elaborated by Rogers about each mentioned exponent. It was found that those appropriations, although punctual, were important for Rogers' circulation in the American academic context. However, it is a misunderstanding considering Rogers exclusively as a functionalist psychologist, or a pragmatist one, because he did not give continuity to those prospects. The study, finally, highlights the need for further investigations on other historical bases of influence in Rogers' theory.
\end{abstract}

Keywords: Carl Rogers; Functionalism; History of Psychology; Pragmatism; Client Centered Therapy.

Resumen: Resulta posible identificar, en la teoría de Carl Rogers, influencias que merecen ser revisitadas. Es sabido que Rogers fue un pensador atento al contexto de ideas que influyeron en la cultura académica estadounidense. Tal atención dialoga con la complejidad de diversas influencias sobre su obra. Este artículo tiene como objetivo analizar algunas de las ideas psicológicas y filosóficas que influenciaron a Rogers. Se entiende que ejercieron influencias directas en el pensamiento rogeriano: el Funcionalismo de John Dewey, Leta Hollingworth y Kurt Goldstein; y el Pragmatismo de John Dewey y William Kilpatrick. Según una perspectiva metodológica histórica crítica, se ha elucidado cómo cada perspectiva de influencia se desarrolló en EEUU, especialmente en las universidades de Chicago y Columbia. En seguida se han identificado los aportes contactados y elaborados por Rogers de cada exponente mencionado. Se ha constatado que esas apropiaciones, aunque puntuales, fueron importantes para la circulación de Rogers en el contexto académico estadounidense. No obstante, lleva a equivoco pensar en Rogers exclusivamente como un psicólogo funcionalista o pragmatista, dado que él no dio continuidad a estas perspectivas. El estudio, finalmente, ha destacado la necesidad de profundizar las investigaciones sobre otras bases históricas de influencia en la teoría rogeriana.

Palabras-clave: Carl Rogers; Funcionalismo; Historia de la Psicología; Pragmatismo; Terapia Centrada en el Cliente.

\section{Introdução}

Carl Rogers foi um psicólogo estadunidense conhecido por suas contribuições em aconselhamento psicológico, em psicoterapia e em terapias grupais. Ao longo de sua trajetória, ele reconheceu que o seu pensamento recebeu distintas influências que possibilitaram o desenvolvimento do seu trabalho (Rogers \& Russell, 2002). Rogers estabeleceu interlocução com diferentes campos da Ciência (psicológica, biológica, física e química), Filosofia (pragmatista, existencialista e fenomenológica), Epistemologia (paradigmas positivistas, holísticos, sistêmicos e 
fenomenológicos) e Psicoterapia (Existencial e Psicanálise). Contudo, não se preocupou em sistematizar uma senda histórica sobre suas influências teóricas e práticas, deixando esse trabalho para os seus estudiosos.

Ressalta-se que, a despeito de realizar uma investigação sobre a teoria de Rogers, suas influências e contribuições não podem ser compreendidas isoladas do Zeitgeist vivido por ele. Entende-se Zeitgeist em referência a um contexto científico de ideias que afetam a cultura, a preocupação e a produção intelectual de um determinado período histórico (Penna, 2000). Conforme apontam Ernest Hilgard, David Leary e Gregory McGuire (1998), é preciso atentar para as falácias históricas da distinção entre grandes homens (expoentes da Psicologia) e o Zeitgeist, dado que ambos os termos não devem ser considerados isolados, pois não se pode supor um prosseguimento unilateral da influência de um pensador sobre os seus fatores contextuais e vice-versa. Com base nesse argumento, pergunta-se: que aspectos do Zeitgeist de Rogers poderíamos observar, caso pudéssemos lançar nova luz sobre ele ou compreendê-lo sob outra perspectiva, no caso, a histórica? Considera-se, portanto, que uma possibilidade de resposta à pergunta feita se encontra no entendimento de que os aspectos aludidos são o Zeitgeist psicológico e filosófico que Rogers contatou nos EUA.

Ponderando essa linha de entendimento sobre as influências deparadas por Rogers, este artigo, de cunho ensaístico, objetiva revisitar, didaticamente, algumas relações históricas desse psicólogo com o Funcionalismo e o Pragmatismo estadunidenses das décadas de 1920-1950. Ressalta-se que essas perspectivas foram familiares a ele durante o período de doutoramento no Teachers College da Universidade de Columbia (entre 1926-1931) e de elaboração teórica e prática na The Society for the Prevention of Cruelty to Children (de 1928 a 1938), na Universidade de Ohio (entre 1938-1945) e na Universidade de Chicago (de 1945 a 1957) (Rogers \& Russell, 2002).

Destaca-se que o artigo aborda, especificamente, o Funcionalismo de John Dewey, Leta Hollingworth e Kurt Goldstein, assim como o Pragmatismo de John Dewey e William Kilpatrick, em razão de Rogers mencionar explicitamente as influências desses autores em suas obras (Rogers, 1959/1977, 1951/1992, 1961/1997, 1977/2001) e entrevistas transcritas (Frick, 1971/1975; Evans, 1975/1979; Rogers \& Russell, 2002).

Para estudos relacionados ao tema, indicamos os trabalhos de Cavalcante (2008) e Moreira (2010), que apontam a existência de uma influência do Pragmatismo em Rogers, a partir do contato com Kilpatrick na Universidade de Columbia. Nessa mesma direção, Castelo-Branco, Cavalcante e Sousa (2008) desenvolvem uma intelecção sobre as influências do Pragmatismo de Dewey em Rogers pela concepção de crescimento organísmico e o seu impacto nos conceitos de experiência e experenciação. Almeida (2009), por sua vez, desenvolve as contribuições de Dewey, em sua noção de apreço (prizing) e postura de não julgamento, na construção rogeriana do conceito-atitude de consideração positiva incondicional.

Em um conjunto de trabalhos comparativos de Rogers com outras perspectivas de pensamento, Moreira (2010) elucida as influências de Kurt Goldstein sobre Rogers e Frederick Perls, para discutir suas convergências e divergências. Castelo-Branco (2012) faz algo semelhante ao apontar o pragmatismo de William James como elemento de influência e mediação para refletir as possíveis aproximações e distanciamentos entre Rogers e Alfred Schutz. Maia, Germano e Moura (2009) reconhecem, também, a matriz pragmática no conceito rogeriano de self, como função simbolizadora da experiência, e aproximam a Psicologia de Rogers ao construcionismo linguístico da Psicologia Narrativa.

No campo das produções internacionais sobre o tema, Kirschenbaum (2007), em uma extensa biografia de Rogers, pontua, suscintamente, os contatos dele com Leta Hollingworth, John Dewey, William Kilpatrick e Kurt Goldstein; enquanto Elliot e Farber (2010) ponderam o idealismo pragmático de pesquisa utilizado por Rogers e suas contribuições para o campo da Psicologia Clínica.

Todos os trabalhos anteriormente citados, em comum, reconhecem as influências funcionalistas e, sobretudo, pragmáticas no pensamento rogeriano. Embora sejam profícuos ao entendimento da teoria de Rogers, esses trabalhos, de um modo geral, desenvolvem-se a partir de menções sucintas, que não articulam as suas influências funcionalistas e pragmatistas e não as especificam no contexto histórico em que ele as conheceu e delas se apropriou nos EUA, instigando um aprofundamento sobre o tema neste artigo.

\section{Método}

Para cumprir o objetivo de responder à pergunta lançada na introdução, esse trabalho se inspirou nas contribuições de Hilgard et al. (1998), que postulam uma perspectiva metodológica histórica-crítica que articula o desenvolvimento de uma teoria psicológica com o seu contexto social, analisando a relação de certos autores com o seu Zeitgeist, sobretudo, institucional. Assim,

As características demográficas dos psicólogos têm-se tornado importantes temas de pesquisa, e a elucidação dos contextos dentro dos quais o progresso das carreiras e outras recompensas têm sido alocadas na História da Psicologia abriu novas e importantes áreas de pesquisa, nas quais as abordagens historicistas estão permitindo descobrir informações e dando origem a interpretações de considerável interesse e valor (p. 413).

Nesse sentido, Hilgard et al. (1998) apontam que esse tipo de pesquisa deve seguir uma elaboração metodológica 
própria à criatividade dos seus pesquisadores sobre o modo de proceder uma investigação relacionada ao tema de estudo. Com efeito, este artigo utiliza uma visada bibliográfica analítico-reflexiva do contexto de ideias psicológicas estadunidenses para situar e especificar suas influências em Carl Rogers. Para tanto, combina uma abordagem externalista, do Zeitgeist funcionalista e pragmatista com o qual Rogers se deparou nos EUA, e internalista, do seu construto teórico. Destarte, procede-se da seguinte maneira: inicialmente, define-se o que é o Funcionalismo e como essa vertente da Psicologia se propagou nos EUA, com base nos estudos relacionados às universidades de Chicago e de Columbia, desdobrando-se em uma Filosofia pragmatista; em seguida, pondera-se o que Rogers contatou, apropriou e elaborou desse Zeitgeist em sua teoria.

\section{Preâmbulo sobre o surgimento do funcionalismo na psicologia estadunidense}

O vocábulo Psicologia funcionalista foi empregado, pela primeira vez, por Edward Titchener, em um artigo publicado em 1898, intitulado Structural and functional psychology to philosophy, com o desígnio de distinguir a Psicologia que se constituía nos EUA daquela que estabelecida por Wilhelm Wundt na Alemanha, assinalada como Psicologia estruturalista (Araújo, 2010). Em linhas gerais, para Titchener, a Psicologia estruturalista entendia que os processos psíquicos se impetravam como uma estrutura. A Psicologia funcionalista, por sua vez, argumentava que o psiquismo somente podia ser entendido como uma função adaptativa do organismo ao ambiente. Ambas as perspectivas concordavam que o objeto de estudo da Psicologia era a experiência, mas discordavam sobre como concebê-la (Ferreira, Schimidt \& Starosky, 2010).

Tal entendimento distintivo foi possível mediante o fato de que Titchener era doutorando de Wundt na Universidade de Leipzig, e, posteriormente, foi para os EUA, onde lecionou na Universidade de Cornell e traduziu as obras do seu orientador. Titchener presenciou, pois, a assunção de duas perspectivas basilares da Psicologia moderna, a saber, a Psicologia wundtiana e a Psicologia funcionalista (Araújo, 2010).

Nos EUA, muitos psicólogos assumiram as nomenclaturas postuladas por Titchener e começaram a organizar um entendimento sobre a Psicologia que se formava no país. Por exemplo, segundo o pensamento de James Angell (1907/1971), a Psicologia estadunidense nasceu como "Um reflexo do interesse predominante pelas formulas mais amplas da biologia e, principalmente, das hipóteses evolucionistas (...); em parte é um eco da mesma tendência filosófica que tem sido ouvida como Pragmatismo, Humanismo e até como Funcionalismo" (p. 622). Tal acepção demarca uma distinção do Funcionalismo em relação à Psicologia Estruturalista, notoriamente voltada para uma orientação inspirada na fisiologia anatomista.
O Funcionalismo, com efeito, se opôs à Psicologia alemã exercida por Wundt e ao Estruturalismo estadunidense desenvolvido por Titchener (Araújo, 2010; Ferreira et al., 2010). A crítica funcionalista consistiu em apontar que esses pensadores elaboraram uma Psicologia reduzida ao entendimento dos processos mentais como elementos estáticos e que, consequentemente, suas pesquisas experimentais culminavam em abstrações do material mental em relação ao seu ambiente (Heidbreder, 1933/1981).

O interesse fundamental da Psicologia funcionalista, decerto, foi investigar a atividade mental consciente como parte de uma corrente maior de forças biológicas que operam a todo o momento. Essa perspectiva considera que "(...) a mente desempenha um papel principal em todas as adaptações ambientais de animais que a possuem" (Angell, 1907/1971, p. 623). Com base nisso, um grupo de psicólogos estadunidenses tenderam a considerar os processos mentais não como elementos abstratos que participam de uma composição maior (estrutura), mas como operações organísmicas que conduzem a atividades de adaptação e produzem efeitos práticos no ambiente (Marx \& Hillix, 1963/1976).

Ressalta-se que o Funcionalismo possui como fundamento uma intencionalidade organísmica caracterizada pela busca da realização de metas adaptativas com base em operações de autorregulação ante os obstáculos ambientais (Figueiredo, 1991). A mesma lógica se aplica à consciência, entendida como “(...) uma operação seletiva e auto-reguladora de táticas comportamentais. Uma operação pressupõe um interesse e a identificação dos interesses correspondentes à análise funcional dos processos psicológicos e comportamentais" (p. 78). A ênfase nos processos mentais conscientes se revela importante para investigar como o organismo se adapta e se comporta. A lógica funcionalista entende, pois, que a consciência surge quando o organismo está em decurso de adaptação a um ambiente ou formando um hábito, tendendo a não operar quando ocorre uma adaptação ou a fixação desse hábito (Heidbreder, 1933/1981).

O Funcionalismo, em suma, consistiu em uma proposta de Psicologia de orientação biológica, que enfatizou os aspectos práticos da experiência consciente na resolução de problemas cotidianos (Ferreira et al., 2010). Conquanto, atualmente, tal corrente psicológica seja extinta, é possível encontrar desdobramentos de suas ideias nas Psicologias Comportamental, Genética, Personalista, Cognitivista, Humanista e Evolutiva.

\section{O desenvolvimento do funcionalismo e do pragma- tismo nas universidades de Chicago e Columbia}

No final do século XIX, e início do XX, os ideais funcionalistas se propagaram em distintas universidades estadunidenses, sendo que diversas foram as situações que possibilitaram isso. Aponta-se, em específico, um contexto 
de urbanização exorbitante, o que gerou imperativos políticos que solicitaram, das universidades, teorias e práticas capazes de examinar e ajustar indivíduos ao contexto social (Ferreira \& Gutman, 2007). O avanço urbanístico e a apelação política culminaram, também, em um movimento de expansão universitária. Nesse contexto, foram inauguradas as universidades de Chicago e de Columbia, que receberam e desenvolveram, fundamentalmente, o Zeitgeist funcionalista em pesquisas relacionadas aos campos da Educação e da Clínica. Com esse advento, a Psicologia dos laboratórios conviveu com a emergente complexidade das intervenções em contextos escolares, clínicos, industriais e empresariais.

Dessa profusão universitária se beneficiou um grupo de psicólogos filiados às ideias de William James e críticos da Psicologia germânica. Ressalta-se que muitas ideias funcionalistas foram inspiradas na obra jamesiana intitulada Principles of Psychology (1890), em especial, na pressuposição evolucionista de que os fenômenos biológicos e psicológicos se equiparam durante os processos adaptativos do organismo ao ambiente (Ferreira \& Gutman, 2007).

O Funcionalismo, contudo, somente deixou de ser um esboço para adquirir um plano de consistência próprio e institucional a partir dos aportes de John Dewey e James Angell. Em 1894, ambos foram contratados pela recém-fundada Universidade de Chicago, onde Angell se tornou diretor do Departamento de Psicologia e Dewey exerceu funções de direção universitária (Heidbreder, 1933/1981).

Dos escritos que subsidiam a Psicologia funcionalista, com efeito, os mais relevantes se concentraram naqueles inspirados pelos estudos de Dewey, que “(...) desenvolveu uma posição organísmica, sublinhando o comportamento como uma coordenação total que adapta o organismo a uma situação" (Marx \& Hillix, 1963/1976, p. 199). A compreensão deweyana sobre a atividade mental se encontra publicada, em 1896, no artigo The Reflex Arc Concept in Psychology, considerado o ponto de partida do Funcionalismo. Dewey (1896/1971) argumenta que, a despeito de existir um circuito sensório-motor que funciona em um sistema arco-reflexo presente no organismo, há um circuito mental de conteúdos que não representa uma substituição de um estímulo sensorial por uma resposta motora. O sistema arco-reflexo, portanto, é uma simplificação da ação humana, dado que o organismo não é um receptor passivo de estímulos, pois é ativo ao percebê-los.

Dewey (1896/1971) considerou que a teoria do sistema arco-reflexo “(...) não é nem física (ou fisiológica) nem psicológica; é uma suposição mista de materialismo e espiritualismo" (p. 398). Para o autor, esse dualismo não serve à Psicologia, por deixá-la desconexa do ponto de vista da espécie humana e da consciência. A Psicologia necessita, pois, de outro princípio de ciência que unifique a existência psíquica, fisiológica e ambiental dentro de uma totalidade.
Dewey defendeu a noção de que o comportamento deve ser enunciado tal como opera e que o seu funcionamento não pode ser reduzido a um sistema de estímulo-resposta, pois essa análise elementarista desconsidera o funcionamento total do organismo. Após esses estudos, Dewey passou a se ocupar com reflexões em Educação e Filosofia, elaborando um programa de educação progressiva. Em 1904, ele se transferiu para o Teachers College da Universidade de Columbia, permanecendo ali até a sua aposentadoria, em 1930. Esse departamento incentivava que a Psicologia deveria prover fundamentos para a Educação e para o desenvolvimento humano. Nele, se destacaram as pesquisas de Leta Hollingworth em Psicologia Clínica e Educacional com crianças consideradas desajustadas socialmente (Pickren \& Rutherford, 2010).

Com a saída de Dewey, Angell (1907/1971) deu prosseguimento às ideias de seu mestre. Ao elaborar os princípios da Psicologia funcionalista, esse autor reconhece que esta modalidade necessita “(...) discernir e apresentar as operações típicas da consciência, sob as condições reais, em vez de tentar analisar e descrever seu conteúdo elementar e complexo" (p. 619). Angell foi sucedido na direção de Departamento, em 1919, por Harvey Carr, que entretanto, deu seguimento às proposições funcionalistas, enfatizando, experimentalmente, mais o comportamento do que a consciência (Marx \& Hillix, 1963/1976).

Nos anos em que esteve na Universidade de Columbia, Dewey continuou a seguir a concepção funcionalista, porém, não mais sob a égide psicológica, mas filosófica. Dewey tentou usar a lógica funcionalista para tecer uma crítica à Filosofia que, segundo ele, reduzia toda experiência a objetos de contemplação, distanciando o conhecimento dela (Waal, 2004/2007). Para refinar tal proposta, Dewey se aproximou do Pragmatismo de Charles Pierce e William James.

Dewey fundou, pois, uma perspectiva pragmatista com inspiração funcionalista na Universidade de Columbia. Cabia aos cientistas e filósofos não ficarem restritos apenas a abstrações, mas elaborarem modelos de práticas que fossem úteis à resolução de problemas e ao desenvolvimento do organismo. Dewey afirmava que a aquisição de conhecimento ocorre na experiência do organismo por meio da reflexão, como função original para resolver situações conflitantes e tensões que passam por emoções, sentimentos e interesses (Waal, 2004/2007).

Ao unir a lógica funcionalista ao Pragmatismo, Dewey (1919/1959) possibilitou nova luz para a natureza da experiência e da mente, antes entendidos como receptáculos passivos ao ambiente. Segundo ele, “(...) o ajuste adaptativo não é completamente passivo; não é uma simples questão de deixar o organismo se moldar pela ambiência (...). Não existe, no ser vivo, coisa que seja mera conformidade às condições” (p. 103). Para Dewey (1919/1959), a experiência tem caráter libertador por se abrir para o novo, adentrando um esforço pelo progresso. Consequentemente, “(...) a experiência se faz ela própria construtiva 
e autorreguladora” (p. 110); e a Ciência é algo que "(...) nasce e se comprova na experiência, e que, depois, é utilizado mediante as invenções para expandir e enriquecer por mil meios a experiência” (p. 110). Toda racionalização científica deve ser posta à prova pela experiência. Do contrário, serão apenas dogmas.

No Teachers College da Universidade de Columbia, Dewey se associou a William Kilpatrick, um notório seguidor do seu pragmatismo que desenvolveu suas ideias em pesquisas sobre processos de transformação educacional e social pela valorização da experiência do aluno (Severino, 2011).

Cabe frisar que, no período de 1934-1945, a Universidade de Columbia recebeu Kurt Goldstein, um médico biologista alemão, conhecido pelos seus estudos em psicopatologia e autorregulação do organismo (Spiegelberg, 1972). Nesse tempo, Goldstein $(1939,1940)$ publicou duas obras influenciadas pelos aportes de James ${ }^{1}$ e Dewey e pelas contribuições da Psicologia da Gestalt para repensar as enfermidades organísmicas sob um ponto de vista mais holístico. Cumpre frisar que Goldstein elaborou a noção de tendência à autorrealização (self-actualizantion tendency) ${ }^{2}$, para o qual o

comportamento normal corresponde a uma mudança contínua de tensão. De tal modo, uma vez que o estado de tensão é alcançado, isso estimula e permite o organismo a realizar-se em mais atividades consoantes à sua natureza. (...) um organismo é regido por uma tendência a realizar, tanto quanto possível, suas capacidades individuais, sua 'natureza' no mundo. Essa natureza é o que chamamos de constituição psicossomática, e na medida do considerado durante uma determinada fase, esse é o padrão individual, o 'caráter' do qual a respectiva constituição atingiu o curso da experiência. Essa tendência para realizar a sua natureza, seu 'si mesmo', é o impulso básico, o único impulso através do qual a vida do organismo é determinada. Essa tendência padece, no ser humano doente, uma mudança de característica (Goldstein, 1939, p. 196, tradução nossa).

\section{No entanto, Goldstein (1940) ressalva que}

somente se pode entender a conduta da autorrestrição humana, caso seja admitida uma tendência

\footnotetext{
1 No biênio de 1938-1939, Goldstein foi convidado pela Universidade de Harvard para homenagear a cátedra de William James realizando uma série de cursos e conferências sobre ele.

2 A noção de tendência à realização é permeada por uma imprecisão de tradução para o português brasileiro. A noção de Selbstverwirklichung, oriunda do alemão, vincula-se a um modo de ver-se a si mesmo como realmente é, ou seja, descreve uma compreensão verdadeira de si em uma forma harmoniosa e integradora. Essa noção foi traduzida como self-actualization para o inglês e como individuação e auto-atualização para o português. Como a língua inglesa, todavia, não comporta o termo actualization como atualização, mas sim realização, uma tradução mais correta é autorrealização.
}

subjacente, que é própria da natureza humana. Como disse John Dewey: 'as ideias envolvidas em tal conduta movem algo na natureza humana e provocam no homem uma resposta ativa'. Se não for assim, somente existirá uma luta de todos contra todos, num estado em que nenhuma vida social poderia originar-se, imperando uma lei da selva (p. 168, tradução nossa).

Percebe-se, enfim, que a influência do Funcionalismo e do Pragmatismo na Psicologia iniciou-se na Universidade de Chicago com Dewey e Angell e estendeu-se a outros pensadores docentes da Universidade de Columbia, a saber: Hollingworth, Kilpatrick e Goldstein, via Dewey. Em suma, o Funcionalismo deweyano se caracteriza pelo entendimento do organismo como uma totalidade que se relaciona com o meio, de modo a incluir todas as funções mentais e corporais. O Pragmatismo deweyano, por seu turno, é uma corrente filosófica que se apropria dos aportes funcionalistas para elaborar uma teoria do conhecimento, que tem como base a experiência, oriunda da interação do organismo com o ambiente como fator de transformação (modificação) de hábitos.

\section{O contato de Carl Rogers com o funcionalismo e o pragmatismo estadunidenses}

Carl Rogers se tornou Ph.D. em Psicologia Clínica e Educacional na Universidade de Columbia e desenvolveu sua docência e pesquisas clínicas na Universidade de Chicago. Sua perspectiva tratou da relação entre organismo e ambiente, em seu caráter de ajustamento e adaptação (autorregulação), sem recair no paradigma de estímulo-resposta (Rogers, 1951/1992, 1942/2005). Ao refletir sobre a consciência, o psicólogo não se prendeu a estruturas e elementos, mas às suas funções mediante a organicidade da pessoa.

Durante o doutorado, Rogers recebeu orientação e influência de Leta Hollingworth, ao investigar processos de ajustamento e desajustamento em crianças. No que concerne a ela, Rogers (1961/1997) indica que iniciou sua predileção clínica e de pesquisas com crianças em virtude da influência dessa pesquisadora. Como consequência, ele se dedicou ao tratamento clínico de crianças consideradas desajustadas e à criação de um inventário de traços e fatores para avaliar níveis de ajustamento da personalidade (Rogers, 1939/1978).

No início da carreira docente, Rogers trabalhou sob a égide do aconselhamento psicológico, uma modalidade clínica que objetiva a adaptação satisfatória do indivíduo ao seu contexto psicossocial, oferecendo-lhe uma série de contatos diretos e intensivos de modo a proporcionar assistência na alteração de suas atitudes e comportamentos (Rogers, 1942/2005; Schmidt, 2009).

O aconselhamento psicológico é um desdobramento aplicado do Funcionalismo estadunidense, que se 
distingue da Psicoterapia, por não enfocar o histórico de vida da pessoa - o que demanda muitas sessões - e não analisá-la em termos de sintomas e doenças (Scheeffer, 1973). Em outra perspectiva relacional de ajuda, o aconselhamento psicológico enfatiza a tensão que o indivíduo sofre, de modo a: identificar qual é o fator situacional que desencadeou o conflito psicológico; diagnosticar, em termos de desadaptações ou desajustamentos, o que isso acarreta para o indivíduo; e situar um plano de intervenções para gerar adaptações ou ajustamentos mais satisfatórios. Por esse plano de trabalho, o aconselhamento psicólogo não requer muitas sessões e não se restringe ao setting clínico, passando a ser utilizado amplamente em contextos organizacionais, educacionais etc. (Rogers, 1942/2005; Schmidt, 2009).

Rogers (1939/1978) chegou a trabalhar nessa perspectiva clássica de aconselhamento psicológico, entretanto, questionou o excesso de investimento em testes psicológicos e a falta de desenvolvimento relacional. Rogers (1942/2005) argumenta que o aconselhamento psicológico deve situar a tensão do indivíduo e trabalhar os seus processos de adaptação e ajustamento. Ele critica, todavia, que tais processos não devem ocorrer em função do que o contexto psicossocial (ambiente) estabelece para o cliente. Ao contrário, deve acontecer em função daquilo de que o cliente se apropria de sua tensão e situação, conforme suas emoções e percepções, para elaborar decisões mais satisfatórias e estabelecer o que lhe é mais apropriado em termos de adaptação e ajustamento. Essa proposta ficou conhecida como aconselhamento não-diretivo.

Seguindo o lastro funcionalista, nos anos em que trabalhou na Universidade de Chicago, Rogers (1951/1992) foi cuidadoso em não adentrar em questões filosóficas gerais do tipo “o que é realidade?” ou “o que é a verdade?”. O autor procurava sempre se restringir e se manter leal às suas observações e pesquisas clínicas para formular sua teoria, entendendo-a como um plano hipotético submetido, constantemente, à prova (Rogers, 1959/1977).

Outra importante elaboração funcionalista em Rogers diz respeito à sua concepção de experiência e consciência. Para ele, experiência refere-se a “(...) tudo o que se passa no organismo em qualquer momento e que está potencialmente disponível a consciência (...) e engloba, pois, tanto os acontecimentos de que o indivíduo é consciente quanto os fenômenos de que é inconsciente” (Rogers, 1959/1977, p. 161). Em relação à consciência, Rogers (1959/1977) a entende como um componente vinculado à experiência e ao ato de experimentar ${ }^{3}$. Segundo ele, a consciência se trata de um ato de simbolizar a experiência. Nesse ponto, Rogers se aproxima da proposta de Dewey ao atentar para a inter-relação entre o organismo e a consciência. Esta é

\footnotetext{
Observa-se que Rogers (1951/1992) diferencia experiência de experimento, definindo que o segundo conceito se vincula a um ato de perceber no organismo suas reações em nível de sensação, emoção e sentimento.
}

considerada uma operação que emerge do organismo para simbolizar o que se experimenta nele.

No Funcionalismo, a adaptação ao ambiente é o âmago da mente funcional, de modo que a consciência é um instrumento do organismo para se adaptar às demandas do ambiente. O ápice do Funcionalismo de Rogers (1977/2001) se apresenta quando ele argumenta que o ser humano conta com a consciência como uma faceta evolutiva do organismo. Em outras palavras, a consciência permite ao organismo reconhecer, identificar e iluminar os elementos que afetam o seu funcionamento, além de lhe permitir conhecer o seu ambiente.

Segundo Rogers (1977/2001), a consciência surge de uma tensão que se instaura entre o organismo e o ambiente. A função da consciência é eliminar o conflito que emerge da aludida tensão, seja por via da modificação do ambiente ou por uma alteração do próprio comportamento. Nesse aporte, a função autorreguladora da consciência consiste em identificar e eliminar os fatores que a evocam. O fato é que o organismo sempre busca se realizar o quanto pode, e em qualquer escala de necessidades, básicas ou complexas. Conforme isso ocorre, o organismo muda a sua relação com o ambiente.

Ressalta-se que a incongruência (fonte de diversas desorganizações psíquicas e organísmicas) surge, também, da mesma forma que a consciência, ou seja, de uma tensão entre organismo e ambiente. Por isso, Rogers (1977/2001) atribui maior ênfase a um contato mais incisivo com a experiência organísmica direta do que com a consciência como instância psíquica. Rogers (1977/2001), destarte, passa a conceber uma brecha entre a consciência e as direções do organismo como um condicionamento cultural que reforça comportamentos destrutivos deturpadores das direções naturais da vida. Uma alienação organísmica não faz parte da tendência à realização, mas se configura como a base de toda patologia psicológica e social. Esse funcionamento canaliza uma autorregulação para comportamentos não realizadores e tomados como destrutivos. Tal concepção estabelece uma lógica funcionalista em que todos os fenômenos biológicos, psicológicos e sociais, patológicos ou não, devem ser entendidos com amparo em um monismo organísmico. O pensamento rogeriano apresenta, pois, a tese funcionalista de que “(...) qualquer fenômeno de natureza psíquica deveria expressar a simultânea presença de determinantes biológicos e sociais" (Penna, 2006, p. 26).

Sobre a noção de tendência à realização (actualization tendency), Rogers (1951/1992) se apropria de uma proposição funcionalista, semelhante à de James Angell, que reconhece que essa tendência é uma corrente maior de força que se torna presente em qualquer fase do desenvolvimento organísmico. Desse modo, o organismo tende a se autorregular e a crescer em relação aos seus determinantes ambientais e orgânicos, tornando-se mais autogovernado. Embora Kurt Goldstein tenha lecionado em Columbia após o doutoramento de Rogers, este o 
menciona, com constância, em suas obras situadas na década de 1950, em especial, em sua teoria da personalidade e do comportamento, a qual argumenta que o desenvolvimento da personalidade ocorre, inicialmente, com o apoio das autorregulações e busca por autorrealizações do organismo. No entendimento de Rogers (1951/1992),

Considerando-se que a tendência atualizante rege todo o organismo, ela se exprime igualmente no setor da experiência que corresponde à estrutura do 'eu' - estrutura que se desenvolve à medida que o organismo se diferencia. Quando há acordo entre o 'eu' e o 'organismo', isto é, entre a experiência do 'eu' e a experiência do organismo', na sua totalidade, a tendência atualizante funciona de maneira relativamente unificada. Ao contrário, se existe conflito entre os dados experienciais relativos ao 'eu' e os relativos ao ‘organismo', a tendência à atualização do organismo pode ser contrária à tendência à atualização do 'eu' (p. 161).

Ainda na aludida teoria, é interessante notar que Rogers (1951/1992) ressalva que, depois de constituída, a personalidade não perde o apoio do organismo, mas o afeta em suas autorregulações.

No que concerne à influência do Pragmatismo em Rogers (1961/1997), este - em retrospectiva de sua carreira - assume uma premissa que sintetiza sua posição pragmatista ao acentuar a supremacia de sua experiência como crivo para submeter e validar todas as ideias alheias e próprias, de modo a obter uma verdade. Rogers (1961/1997) salienta que nunca encontrou diretamente Dewey, mas contatou sua perspectiva pragmatista com a interveniência de William Kilpatrick, um de seus professores no Teachers College (Frick, 1971/1975).

Ao elaborar a noção de consideração positiva incondicional (unconditional positive regard), Rogers (1959/1977) apresenta uma influência deweyana em sua teoria. Segundo o autor,

(...) experimentar um sentimento de consideração positiva incondicional a respeito de uma pessoa significa 'apreciar' esta pessoa. No sentido que atribuímos a este termo - sentido tomado de Dewey - o indivíduo é estimado como pessoa e independente dos critérios que se poderia aplicar aos diversos elementos de seu comportamento. (...) outro termo que, de uma maneira geral é sinônimo de apreciação e de consideração positiva é o termo aceitação. Este se presta, no entanto, a certos mal-entendidos que a noção de apreciação tende a afastar. (...) Como se pode adivinhar é sem dúvida, esta atitude de aceitação incondicional que cria as condições necessárias à realização do estado de acordo interno e, deste modo, do funcionamento adequado (p. 175-176).
Com efeito, Rogers (1959/1977) se aproxima de Dewey ao buscar apropriações do que se passa no organismo, para, com base nisso, reconhecer quais experiências e valores são autênticos, ou não, a ele. Assim, as atitudes, percepções e sensações moleculares passam a ser molares e integradas com os princípios da tendência à realização.

As perspectivas de Rogers e Dewey convergem quanto à concepção de crescimento no qual o organismo está imerso (Castelo-Branco et al., 2008). Essa compreende “(...) o crescimento como algo dinâmico, interacional e contínuo que se aplica a toda natureza e que nunca alcança um produto completo em si” (p. 131). Eis por que “(...) a realidade pode ser continuamente (re)ordenada e (re)construída, de forma a permitir uma prática psicoterapêutica centrada nas experiências de cada indivíduo" (p. 131). Ambas as perspectivas divergem, entretanto, quanto à concepção de liberdade. Dewey acredita que esse crescimento é externo ao indivíduo em razão das forças naturais e da sociedade, mas esse crescimento poderia ser moldado por meio da Educação. Rogers, por outra via, não acredita que se possa moldá-lo, visto que a única condição para o crescimento é deixar as coisas serem como são, sem distorcê-las (Castelo-Branco et al., 2008). Por esse motivo, Rogers elaborou uma prática de ensino não diretivo, centrado nas experiências significativas do aluno, ao passo que o Pragmatismo de Dewey gerou práticas de educação voltadas para a transformação social - que influenciou, por exemplo, o movimento de Escola Nova no Brasil.

Por fim, cumpre notar que Rogers se apropriou de elementos funcionalistas e pragmatistas estadunidenses para compor certos aspectos de sua teoria, seja de aconselhamento ou de psicoterapia. Tais apropriações, embora pontuais, foram imprescindíveis à edificação de sua abordagem em um contexto de intensa circulação de ideias amparadas pelo Zeitgeist funcionalista e pragmatista. A despeito disso, afigura-se equívoco alocar Rogers exclusivamente como um expoente ou representante das aludidas correntes estadunidenses de pensamento psicológico e filosófico, dado que ele não as continuou.

\section{Considerações finais}

Carl Rogers apresenta uma riqueza de influências históricas explícitas e implícitas, que merecem ser elucidadas, discutidas e reelaboradas. Rogers foi um homem atento às contendas psicológicas e filosóficas que ocorriam nos EUA. Com efeito, intencionou-se conferir uma visão ensaística processual e didática que revisita o pensamento rogeriano no que concerne às suas perspectivas funcionalistas e pragmatistas, reconhecendo a necessidade de mais investigações que aprofundem outras influências que ele tenha recebido.

Destarte, conquanto o pensamento rogeriano seja claro em relação àqueles que o influenciaram, exercitou-se um 
retorno histórico ao Zeitgeist estadunidense funcionalista e pragmatista de Rogers, de modo a elucidar e refletir sobre o que ele contatou e do que se apropriou. Sem tencionar uma repetição, impõe-se evocar, sinteticamente, alguns pontos das influências presentes na teoria de Rogers.

Em relação ao Funcionalismo, Rogers reconhece que a dinâmica de ajustamento e adaptação é o âmago da intervenção clínica em aconselhamento psicológico. No que concerne à Psicoterapia, ele entende a constituição da personalidade em função do organismo e sua relação com o ambiente, através de autorregulações. Rogers entende, ainda, a experiência com base em tudo o que acontece no organismo, e concebe a consciência como uma operação simbolizadora que emerge do organismo quando há uma tensão com o ambiente. Em relação à noção de tendência à realização, Rogers entende que esta alude a uma capacidade do organismo para não somente entrar em equilíbrio homeostático com o ambiente, mas também transcendê-lo e automodificar-se em relação a ele.

No que reporta ao Pragmatismo, Rogers segue uma posição pragmática, ao enfatizar a verdade como um conhecimento que não é interno ou externo ao organismo, mas parte de uma interação com o meio, que é validada pela experiência e possibilita uma construção reflexiva além do habitual. Rogers se apropria do pensamento deweyano para formular a noção de consideração positiva incondicional como uma atitude que aprecia (ação de não impor valor) a experiência alheia. A concepção de crescimento organísmico, como base em um processo que modifica a realidade pessoal e compartilhada, pode ser entendida como outra inspiração pragmatista de Rogers.

Considera-se que tal visada histórica possibilita, pois, algumas ponderações sobre os processos contextuais estadunidenses envolvidos na organização de alguns aspectos da teoria de Rogers, além de apontá-las para os estudiosos da abordagem centrada na pessoa e ampliar os campos de compreensão das diferentes possibilidades de entender à Psicologia Humanista de Rogers no Brasil (Frota, 2012).

Finalmente, é válido assinalar que há outros aspectos do Zeitgeist estadunidense de Rogers a serem reconstituídos historicamente, por exemplo, a relação dele com o movimento fenomenológico na Psicologia dos EUA, nas décadas de 1940-1960, como um novo paradigma de pesquisa empírica em Psicologia e estudos sobre a personalidade.

\section{Referências}

Almeida, L. (2009). Consideração positiva incondicional no sistema teórico de Carl Rogers. Temas em Psicologia, 17(1), 177-190.

Angell, J. (1971). O Funcionalismo. Em R. Herrnstein \& E. Boring (Orgs.), Textos básicos de história da psicologia (p. 617-626., D. M. Leite, Trad.). São Paulo: Editora Herder. (Originalmente publicado em 1907).
Araújo, S. (2010). O estruturalismo de Edward Titchener. Em A. Ferreira (Org.), A pluralidade do campo psicológico (p. 39-52). Rio de Janeiro: Editora UFRJ.

Castelo-Branco, P. (2012). Revisão dos aspectos monológicos de Carl Rogers à luz da fenomenologia social. Revista do NUFEN, 4(2), 83-98.

Castelo-Branco, P., Cavalcante, F., \& Oliveira, H. (2008). Da experiência à experienciação no Pragmatismo em Rogers: implicações para a tendência formativa da ACP. Em F. Cavalcante \& A. Sousa (Orgs.), Humanismo de funcionamento Pleno: tendência formativa na abordagem centrada na pessoa (p. 117-144). Campinas, SP: Alínea.

Cavalcante, F. (2008). Psicologia humanista experiencial. Em F. Cavalcante. \& A. Sousa (Orgs.), Humanismo de funcionamento pleno (p. 21-50). Campinas, SP: Alínea.

Dewey, J. (1959). Reconstrução da Filosofia. São Paulo: Companhia Editora nacional (Originalmente publicado em 1919).

Dewey, J. (1971). Contra a reflexologia. Em R. Herrnstein \& E. Boring (Orgs.), Textos básicos de história da psicologia (p. 394-399., D. M. Leite, Trad.). São Paulo: Editora Herder. (Originalmente publicado em 1896).

Elliott, R., \& Farber, B. (2010). Carl Rogers: idealistic pragmatist and psychotherapy research pioneer. Em L. Castonguay., J. Muran, L. Angus., J. Hayes., N. Ladany. \& T. Anderson (Eds.), Bringing psychotherapy research to life: understanding change through the work of leading clinical researchers (p. 17-27). Washington, DC: APA.

Evans, R. (1979). Carl Rogers: o homem e suas ideias (M. P. Ferreira, Trad.). São Paulo: Martins Fontes. (Originalmente publicado em 1975).

Ferreira, A. \& Gutman, G. (2007). O funcionalismo em seus primórdios: a psicologia a serviço da adaptação. Em A. Jacó-Vilela., A. Ferreira \& F. Portugal (Orgs.), História da psicologia: rumos e percursos (p. 121-140). Rio de Janeiro: Nau.

Ferreira, A., Schimidt, A., \& Starosky, M. (2010). O funcionalismo: a psicologia nos trilhos da adaptação. Em A. Ferreira (Org.), A pluralidade do campo psicológico (p. 71-90). Rio de Janeiro: Editora UFRJ.

Figueiredo, L. C. (1991). Matrizes do pensamento psicológico. Petrópolis, RJ: Vozes.

Frick, W. (1975). Psicologia Humanista: entrevistas com Maslow, Murphy e Rogers. Rio de Janeiro: Zahar Edições. (Originalmente publicado em 1971).

Frota, A. (2012). Origens e destinos da abordagem centrada na pessoa no cenário brasileiro contemporâneo: reflexões preliminares. Revista da Abordagem Gestáltica, 18(2), 168-178.

Goldstein, K. (1939). The organism: a holistic approach to biology derived from pathological data in man. Woodstock: American Book Company.

Goldstein, K. (1940). Human nature in the light of psychopathology. Cambridge: Havard University Press. 
Heidbreder, E. (1981). Psicologias do século XX (L. Blandy, Trad.). São Paulo: Mestre Jou. (Originalmente publicado em 1933).

Hilgard, E., Leary, D. \& McGuire, G. (1998). A história da psicologia: um panorama de avaliação crítica. Em J. Brozek \& M. Massimi (Orgs), Historiografia da psicologia moderna (p. 399-432., J. Ceschin \& P. Silva, Trads.). São Paulo: Unimarco; Loyola.

Kirschenbaum, H. (2007). The life and work of Carl Rogers. Herefordshire: PCCS Books.

Maia, C., Germano, I. \& Moura, J. (2009). Um diálogo sobre o conceito de self entre a abordagem centrada na pessoa e a psicologia narrativa. Revista do NUFEN, 1(2), 33-54.

Marx, M. \& Hillix, W. (1976). Sistemas e teorias em psicologia (A. Cabral, Trad.). São Paulo: Cultrix. (Originalmente publicado em 1963).

Moreira, V. (2009). A gestalt-terapia e a abordagem centrada na pessoa são enfoques epistemológicos? Revista da Abordagem Gestáltica, 15(1), 03-12.

Moreira, V. (2010). Convergências e divergências entre a psicoterapia de Carl Rogers e Frederick Perls. Revista do NUFEN, 2(1), 20-50.

Penna, A. (2000). Introdução à epistemologia. Rio de Janeiro: Imago.

Penna, A. (2006). Os filósofos e a psicologia. Rio de Janeiro: Imago.

Pickren, W. \& Rutherford, A. (2010). The Golden Age of American Psychology. Em W. Pickren \& A. Rutherford, A history of modern psychology in context (p. 208-235). Wiley Hoboken: New Jersey.

Rogers, C. (1977). Teoria e pesquisa. Em C. Rogers \& M. Kinget, Psicoterapia e relações humanas: teoria e prática da terapia não-diretiva (Vol. 1., 2a ed., p. 143-282., M. Bizzoto, Trad.). Belo Horizonte: Interlivros. (Originalmente publicado em 1959).

Rogers, C. (1978). O tratamento clínico da criança problema (U. Arantes, Trad.). São Paulo: Martins Fontes. (Originalmente publicado em 1939).

Rogers, C. (1992). Terapia centrada no cliente (M. J. Ferreira, Trad.). São Paulo: Martins Fontes. (Originalmente publicado em 1951).

Rogers, C. (1997). Tornar-se pessoa (M. J. Ferreira \& A. Lamparelli, Trads.). São Paulo: Martins Fontes. (Originalmente publicado em 1961).

Rogers, C. (2001). Sobre o poder pessoal (W. Penteado, Trad.). São Paulo: Martins Fontes. (Originalmente publicado em 1977).

Rogers, C. (2005). Psicoterapia e consulta psicológica (M. J. Ferreira, Trad.). São Paulo: Martins Fontes. (Originalmente publicado em 1942).

Rogers, C. \& Russell, D. (2002) Carl Rogers: the quiet revolutionary - an oral history. Roseville: Penmarin Books.
Scheeffer, R. (1973). Aconselhamento psicológico (4a ed). Rio de janeiro: Fundo de Cultura.

Schmidt, M. (2009). O nome, a taxonomia e o campo do aconselhamento psicológico. Em H. Moratto., C. Barreto \& A. Nunes (Orgs.), Aconselhamento psicológico numa perspectiva fenomenológica existencial: uma introdução (p. 1-21). Rio de Janeiro: Guanabara Koogan.

Severino, F. (2011). Apresentação à edição brasileira. Em W. Kilpatrick. Educação para uma sociedade me transformação (p. 9-20). Petropolis, RJ: Vozes.

Spiegelberg, H. (1972). Phenomenology in Psychology and Psychiatry. Evaston: Northwestern University Press.

Waal, C. (2007). Sobre o Pragmatismo (C. Rodrigues, Trad.). São Paulo: Edições Loyola. (Originalmente publicado em 2004).

Paulo Coelho Castelo Branco - Professor Adjunto I do Curso de Psicologia do Instituto Multidisciplinar em Saúde da Universidade Federal da Bahia (UFBA), Campus Anísio Teixeira - Vitória da Conquista. Doutor em Psicologia Social pela Universidade Federal de Minas Gerais (UFMG). Mestre em Psicologia pela Universidade Federal do Ceará (UFC). Endereço Institucional: Universidade Federal da Bahia, Campus Anísio Teixeira, Instituto Multidisciplinar em Saúde, Rua Rio de Contas, ${ }^{0} 58$, Gabinete 22, Candeias, CEP: 45.029-094. Vitória da Conquista - Bahia. E-mail: pauloccbranco@gmail.com

Sérgio Dias Cirino - Graduado em Psicologia pela Universidade Federal de Minas Gerais (UFMG). Mestre e Doutor em Psicologia pela Universidade de São Paulo. Bolsista do Programa Pesquisador Mineiro da FAPEMIG. Professor associado no Departamento de Psicologia da UFMG onde orienta alunos de mestrado e doutorado. Pesquisador do Laboratório de Pesquisa e Ensino em História da Psicologia da UFMG. Membro da equipe coordenadora do curso de Pedagogia a distância da da Faculdade de Educação da UFMG. Coordenador do GT de História da Psicologia da Associação Nacional de Pesquisa e Pós-graduação em Psicologia (ANPEPP). Sócio fundador da Sociedade Brasileira de Psicologia (SBHP). Membro do GT de História da Psicologia da Sociedade Interamericana de Psicologia (SIP). Membro da Rede Ibero-americana de Pesquisadores em História da Psicologia (RIPeHP). Membro da Comissão assessora do Museo de Historia de la Psicología de San Luis (Argentina).

Recebido em 19.12.2015 Primeira Decisão Editorial em 22.02.2016 Aceito em 07.04.2016 